\title{
Radiation Control Coatings on Rough-Surfaced Roofs at a Federal Facility: Two Summers of Monitoring Plus Roof and Whole Building Modeling
}

Thomas W. Petrie, Ph.D.

$$
\text { CONF - } 980650 \ldots
$$

Phillip W. Childs

Jeffrey E. Christian

Energy Division

Oak Ridge National Laboratory

To be presented and published in the ASHRAE Symposium Transactions being held in Toronto Ontario, Canada June 20-25, 1998

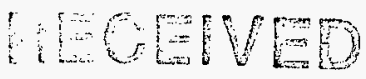

MOQ 938

09 TI

Research sponsored by the Office of Building Technologies and Department of Energy

The submitted manuscript has been authored by a contractor of the U.S. Government under contract No. DE-

AC05-960R22464. Accordingly, the U.S.

Government retains a nonexclusive,

royalty-free license to publish or reproduce

the published form of this contribution, or

allow others to do so, for U.S. Government

purposes.

DISTRISUTION OF THIS DOCUMENT IS UNLIMITED

Prepared by the

MASTER

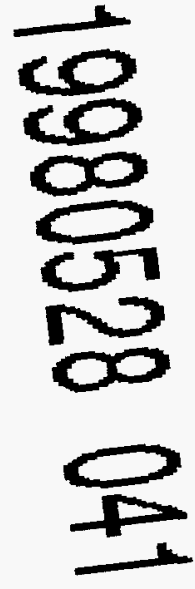

OAK RIDGE NATIONAL LABORATORY

Oak Ridge, Tennessee 37831

managed by

LOCKHEED MARTIN ENERGY RESEARCH CORP.

for the

U.S. DEPARTMENT OF ENERGY

under contract No. DE-AC05-96OR22464 


\section{DISCLAIMER}

This report was prepared as an account of work sponsored by an agency of the United States Government. Neither the United States Government nor any agency thereof, nor any of their employees, makes any warranty, express or implied, or assumes any legal liability or responsibility for the accuracy, completeness, or usefulness of any information, apparatus, product, or process disclosed, or represents that its use would not infringe privately owned rights. Reference herein to any specific commercial product, process, or service by trade name, trademark, manufacturer, or otherwise does not necessarily constitute or imply its endorsement, recommendation, or favoring by the United States Government or any agency thereof. The views and opinions of authors expressed herein do not necessarily state or reflect those of the United States Government or any agency thereof. 


\section{Radiation Control Coatings on Rough-Surfaced Roofs at a Federal Facility: Two Summers of Monitoring plus Roof and Whole Building Modeling}

Thomas W. Petrie, Ph.D.

Phillip W. Childs

Jeffrey E. Christian

Member ASHRAE

Member ASHRAE

\section{ABSTRACT}

Support of the federal New Technology Demonstration Program (NTDP) allowed us to learn the effect of radiation control coatings on roofs at a federal facility in the Panhandle of Florida. Two rough-surfaced, moderately well-insulated, low solar reflectance built-up roofs (BURs) were spray coated with a white, latex-based product with ceramic beads. Samples of the coated roofs were brought periodically to the laboratory to measure the solar reflectance as the coatings weathered. Relative to the uncoated BUR, the fresh coating increased the solar reflectance from 0.09 to about 0.53 . This freshly coated solar reflectance is at least 0.2 lower than we have observed for similar fresh latex- or acrylic-based coatings on smooth surfaces. In the course of the project, the reflectance for one BUR decreased to 0.42 while the other decreased to 0.50 . Other measurements for some white coatings on smooth surfaces that have weathered several years show solar reflectances as low as 0.50 to 0.55 .

Beginning several months before the BURs were coated in July 1996 and ending in October 1997, we monitored the power demand of the all-electric buildings that the roofs covered and temperatures and heat fluxes for two instrumented areas on each roof. The data were analyzed for monthly average performance. The BUR whose reflectance decreased to 0.42 was significantly shaded, including the instrumented areas, by trees to the south of its building. We measured about $271 / 2 \%$ shading of the roof in mid-August in midmorning. The other had a heavyweight concrete deck with some shading away from the instruments.

Average decreases in the sunlit temperatures of the coated vs. the uncoated surfaces show weathering effects. They also show that the shading enhanced the effect of the coating on the significantly shaded roof because the coated instrumented area on it was preferentially shaded near noon of sunny days. For August, September and October of 1996 , the average sunlit surface temperature decreases were $12.9 \%$ on the shaded roof and $12.3 \%$ on the heavyweight roof. The averages for the same two months in 1997 were $11.9 \%$ and $10.7 \%$, respectively.

Whole building models were constructed for DOE 2.1E and model predictions were compared to measurements of total electrical power for each all-electric building. The building with the significantly shaded roof had very high internal loads. The effect of the shading on annual energy use for cooling was twice that of the coating but the coating decreased annual cooling energy needs only by $0.5 \%$. The building with the heavyweight concrete-decked roof had small internal loads. For it, the DOE $2.1 \mathrm{E}$ model predicted a $7.4 \%$ decrease in annual cooling energy use due to the coating and a comparatively small effect of the less extensive shading.

\section{KEYWORDS}

Radiation Control Coatings; Built-up Roof; Weathering; Solar Reflectance 


\title{
Radiation Control Coatings on Rough-Surfaced Roofs at a Federal Facility: Two Summers of Monitoring plus Roof and Whole Building Modeling
}

\begin{abstract}
Support of the federal New Technology Demonstration Program (NTDP) allowed us to learn the effect of radiation control coatings on roofs at a federal facility in the Panhandle of Florida. Two rough-surfaced, moderately well-insulated, low solar reflectance built-up roofs (BURs) were spray coated with a white, latex-based product with ceramic beads. Samples of the coated roofs were brought periodically to the laboratory to measure the solar reflectance as the coatings weathered. Relative to the uncoated BUR, the fresh coating increased the solar reflectance from 0.09 to about 0.53 . This freshly coated solar reflectance is at least 0.2 lower than we have observed for similar fresh latex- or acrylic-based coatings on smooth surfaces. In the course of the project, the reflectance for one BUR decreased to 0.42 while the other decreased to 0.50 . Other measurements for some white coatings on smooth surfaces that have weathered several years show solar reflectances as low as 0.50 to 0.55 .

Beginning several months before the BURs were coated in July 1996 and ending in October 1997, we monitored the power demand of the all-electric buildings that the roofs covered and temperatures and heat fluxes for two instrumented areas on each roof. The data were analyzed for monthly average performance. The BUR whose reflectance decreased to 0.42 was significantly shaded, including the instrumented areas, by trees to the south of its building. We measured about $271 / 2 \%$ shading of the roof in mid-August in midmorning. The other had a heavyweight concrete deck with some shading away from the instruments.
\end{abstract}

Average decreases in the sunlit temperatures of the coated vs. the uncoated surfaces show weathering effects. They also show that the shading enhanced the effect of the coating on the significantly shaded roof because the coated instrumented area on it was preferentially shaded near noon of sunny days. For August, September and October of 1996, the average sunlit surface temperature decreases were $12.9 \%$ on the shaded roof and $12.3 \%$ on the heavyweight roof. The averages for the same two months in 1997 were $11.9 \%$ and $10.7 \%$, respectively.

Whole building models were constructed for DOE 2.1E and model predictions were compared to measurements of total electrical power for each all-electric building. The building with the significantly shaded roof had very high internal loads. The effect of the shading on annual energy use for cooling was twice that of the coating but the coating decreased annual cooling energy needs only by $0.5 \%$. The building with the heavyweight concrete-decked roof had small internal loads. For it, the DOE 2.1E model predicted a 7.4\% decrease in annual cooling energy use due to the coating and a comparatively small effect of the less extensive shading. 


\section{INTRODUCTION}

In December 1995 we began a project with support of the New Technology Demonstration Program (NTDP) of the Federal Energy Management Program to do a test bed demonstration of radiation control coatings on federal buildings. Data include whole building electricity use as well as roof temperatures and heat fluxes for two buildings at a federal facility in the Florida Panhandle. Coating was done in early July 1996. Data acquisition and monthly summarization continued through October 1997.

This project has documented the thermal performance of existing rough-surfaced built-up roofs (BURs) that were covered by a white latex-based coating with ceramic beads. In earlier reports on the project (Petrie, et al., 1998; Petrie and Childs, 1997), we discussed relevant literature, project goals and monitoring protocols, installation of instruments, installation of coatings, and results through the first summer after coating. The solar reflectance of the coatings applied to the built-up roofs was reported for the fresh coatings and after 17 and 33 weeks of weathering. These reflectances were compared to values from uncoated membranes and various coatings on smooth membranes. Although the reflectances for the coated BURs were significantly larger than for uncoated membranes, they were about $20 \%$ lower than observed for white coatings on smooth surfaces. A solar ray is likely to undergo more reflections, with small absorption each time, on coated rough surfaces than on smooth surfaces. The reflectances of the coated rough surfaces, like those of smooth surfaces, showed degradation with time. Surface contamination is likely to cause degradation because non-reflecting particles adhere to the white surfaces.

Since the previous reports, the literature relevant to this project has been supplemented by more field measurements (Parker, et al., 1998a) and more work under the auspices of the Heat Island Project directed toward generalizing the experience with coated roofs and other high albedo surfaces (Parker, et al., 1998b; Akbari, et al., 1998; Konopacki, et al., 1997; Gartland, et al., 1996). Not only are there now more data for coated roofs in the open literature, but more support has been generated in the form of calculations about the impact of high albedo roofs. As an example, results from whole-building annual energy use predictions with the public domain program DOE 2.1E (LBL, 1981; LBL, 1993) are included in the June 1997 draft for public comment of revisions to ASHRAE/IES Standard 90.1-1989 (ASHRAE, 1989). Reflective roofs with initial solar reflectance exceeding $70 \%$ and infrared emittances exceeding $80 \%$ are considered eligible for credit. Modeled reflectance was 55\%, to account for aging effects. The proposed credit is up to $23 \%$ reduction in roof insulation $\mathrm{R}$-value for a reflective roof in cooling-dominated climates.

This paper updates and completes the presentation of data for our NTDP project. Measurements show the history of coated and uncoated outside-surface temperatures and solar reflectances of the roof surfaces from July 1996, when the roofs were coated, through October 1997. Roof models based on onedimensional transient conduction through the roofs are used to compare the heat fluxes through the roof deck for coated and uncoated roof surfaces. DOE2.1E whole building annual energy use predictions 
specific to the buildings and their operating schedules show the effect of the coatings and other building features for the climatic conditions of the Florida Panhandle. 


\section{OVERVIEW OF PROJECT}

The two buildings at the federal facility in the Florida Panhandle which are the focus of this paper had low-slope roofs over 2 in.- $(5.1 \mathrm{~cm}$-) thick, aged polyisocyanurate insulation, a common foam insulation for low-sloped roofs. A layer of gravel was embedded in the top coat of asphalt to complete the four-ply BURs. One building, a convenience store, was significantly shaded by live oak trees to the south. The part of its roof in which instruments were installed, the roof for a storeroom at the east end of the store, was built over a metal deck directly exposed to the storeroom interior. The storeroom roof area was about one-fourth of the total for the convenience store. The rest of the building had a BUR over a wood deck with a plenum and drop ceiling below the roof. The roof of the other building, a veterinary clinic, had a heavyweight concrete deck and lightweight concrete over it, in addition to the insulation and the BUR.

Figure 1 shows cross-sections of the two roofs and placement of heat flux transducers in the middle of the polyisocyanurate insulation in them. Three thermocouples were vertically aligned with each heat flux transducer to comprise a set of instruments for monitoring thermal performance. One thermocouple was attached to the underside of the deck, another was placed on the outside surface and the third junction was about 3 in. $(7.6 \mathrm{~cm})$ above the surface in the outside air. There were two sets of instruments on each roof, one in an area coated in July 1996 and the other, about $2 \mathrm{ft}$ by $2 \mathrm{ft}(0.61 \mathrm{~m}$ by $0.61 \mathrm{~m})$, left uncoated throughout the project. The uncoated areas were masked during coating by pieces of BUR like that on the roofs. These coated loose pieces were weathered along with the rest of the coated areas on each roof. Samples were cut from these pieces periodically to take to a laboratory for measurement of solar reflectances and then stored for a historical record of weathering.

To provide comparisons to the data from the weathered BUR samples and the instrumentation at the two locations on each BUR, solar reflectances and some outside-surface temperatures are also given for two other locations and various coatings. The first additional location on the roof of a fast food restaurant at the federal facility had $2 \mathrm{ft}$ by $2 \mathrm{ft}(0.61 \mathrm{~m}$ by $0.61 \mathrm{~m})$ areas where an acrylic elastomeric coating and the ceramic coating used on the BURs were tested side-by-side. About 3 in. $(7.6 \mathrm{~cm})$ of polyisocyanurate insulation and a plywood deck under a smooth single-ply membrane comprised the restaurant roof. The second additional location was an outdoor test facility at a national laboratory in East Tennessee. The same coatings as used at the federal facility in Florida and two other ceramic coatings were tested during the time frame of the Florida project. Only reflectance data from weathering at this location are included in this paper.

The temperatures and heat fluxes from the six instrumented areas at the federal facility as well as 
the total electricity use from pulse-initiating kilowatt-hour meters in the two buildings with BURs were stored in data loggers in each building as hourly averages of one minute scans until retrieval by modem link at one week to one month intervals. The samples of freshly coated membranes were retrieved during a trip in July 1996 by personnel from the national laboratory to rendezvous with personnel from the ceramic coating manufacturer to clean up the roofs, apply the coating, and check that monitoring technology was functioning after the coating was applied. The samples of weathered coatings were retrieved during trips to the federal facility in November 1996, March 1997 and November 1997 by personnel from the national laboratory. During the last trip the data loggers were disconnected and all instrumentation leads cut off and removed. The heat flux transducers were left embedded in the roofs and the coatings were left intact.

What was left of the coated loose pieces of BUR was left on the coated roofs. 


\section{MEASUREMENTS OF REFLECTANCES AND OUTSIDE-SURFACE TEMPERATURES}

This project documents the effect of white coatings on the thermal performance of rough-surfaced built-up roofs. Solar reflectances and outside-surface temperatures show measurable evidence of this effect. Solar reflectance or albedo is the fraction of incoming solar irradiation that is reflected away from a surface. Since roof membranes, coated or uncoated, are not transparent to solar radiation, what is not reflected is absorbed. If the roof deck is kept at approximately constant temperature and thermal conductivities of roof components remain approximately constant, absorbed solar radiation raises the surface temperature. The lower the reflectance, the more the absorption of solar irradiation and the higher the surface temperature.

Table 1 shows the history of the solar reflectance of various coated and uncoated roof membranes. Fresh and weathered values for a variety of white coatings on both smooth and rough surfaces are included. The coatings are either acrylic elastomeric coatings (RH3, RH2, RH1) or latex-based coatings with ceramic beads added (SHP, VC, TC2, SOL, TC1, INS). The data in this table include updated values from a similar table given earlier (Petrie, et al., 1998) as well as values measured since the earlier data were measured by Yarbrough (1997). In the middle of this project we purchased our own solar spectrum reflectometer from the same manufacturer as Yarbrough's. To ensure there was no error from switching reflectometers, we redid the previous measurements and updated Table 1 with them before doing the rest of the measurements with our instrument.

Figure 2 is a graph of some of the data in Table 1 for perspective on the solar reflectances of samples SHP and VC from the coated BURs. It shows that the solar reflectances of fresh white coatings on smooth surfaces vary from 0.77 to 0.85 . The fresh values on smooth surfaces are more than 0.20 higher than the fresh values on the rough BURs. However, Table 1 shows that the fresh values of 0.53 to 0.54 on the rough BURs are 0.45 higher than the reflectances of the uncoated membranes. The reflectances of the white coated membranes show various rates of decrease with time but all seem to have reached a stable weathered value by the end of two years ( 730 days). A smooth curve is shown through the data for SOL, another for RH2 and RH3, a third for TC1, TC2, INS and RH1 and a fourth for VC and SHP. From the reflectances displayed in Fig. 2 by the coatings on smooth surfaces (all except VC and SHP), Akbari, et al.'s (1998) weathered value of 0.55 is accurate for coatings TC1, INS and RH1 and possibly TC2. It is conservative for coatings RH3, RH2 and SOL. On the rough BURs the weathered value is definitely less than 0.55 with large scatter. No uncoated BUR for reflectance samples was kept on the roofs at the federal facility. The sample yielding the UNC3 data in Table 1 was a piece cut off before the remainder was 
coated along with the roofs. Its history was unknown. Evidence in Table 1 for samples UNC1 and UNC2 shows that the reflectances of uncoated membranes do not appear to change significantly with time as the uncoated surfaces are exposed to climatic conditions.

Table 2 presents values of monthly average sunlit uncoated and coated surface temperatures for the veterinary clinic with the heavyweight concrete-decked roof and for the convenience store with the shaded metal-decked roof. In the absence of evidence from measurements of solar irradiation at the test locations, sunlit is defined in terms of a simple criterion that was applied to each pair of hourly coated and uncoated temperatures during a month. If solar irradiation of the roofs caused an uncoated temperature to be more than $7.5^{\circ} \mathrm{F}\left(4.2^{\circ} \mathrm{C}\right)$ warmer than its corresponding coated temperature, the pair was included in the sunlit average taken at the end of the month. Air temperatures above the coated and uncoated areas were averaged at the same times that the surface temperatures met the sunlit criterion. They are included in Table 2 to provide a measure of how comparable climatic conditions were from month to month.

The conclusion from Table 1 is that the reflectances of samples SHP and VC decrease over the duration of the project but remain much greater than the low reflectance of the uncoated BUR. Thus, the behavior in Table 2 of the average sunlit surface temperatures for the coated and uncoated areas on the veterinary clinic roof is reasonable. The average outside-air and uncoated surface temperatures are about the same in August and September 1997 compared to August and September 1996. Data for July 1996 are not available for the veterinary clinic because they were lost from storage in the veterinary clinic's data logger during an electrical storm in late July 1996. The average coated temperatures in August and September 1997 are higher and the percent decreases lower than during the same months in 1996, which is consistent with lower solar reflectance in 1997 than in 1996. The October 1997 coated temperature is not higher than in October 1996 but the percent decrease is consistent with the comparisons in the hotter months of August and September. From November through April, no data are given because of the few pairs of temperatures that met the sunlit criterion.

Comparisons for three summer months in 1996 and 1997 are available in Table 2 for the convenience store roof. The coated surface temperatures and the percentage decreases show the respective increases and decreases that are expected as white-coated roofs weather. Moreover, the values of the percentage decreases are somewhat higher and the coated surface temperatures are somewhat lower than the respective monthly averages for the veterinary clinic. This is consistent with preferential shading of the coated area in mid-day and the uncoated area in mid-afternoon on sunny summer days at the convenience store. 
To illustrate this preferential shading Figure 3 shows hourly temperatures for two similar days in 1996 just before and after the convenience store roof was coated. Both outside-air temperatures for the coated (lower solid curves) and uncoated (lower dashed curves) locations and the uncoated surface temperatures (upper dashed curves) are affected by the shading but have similar profiles before and after the roof was coated. As the upper solid curves show, there is clearly a beneficial decrease in the surface temperatures from the roof uncoated to the roof coated situation.

In Table 2 for August, September and October 1996 and September and October 1997, the uncoated surface temperatures on the convenience store roof show the effect of shading. They are lower than the corresponding temperatures for the veterinary clinic despite essentially equal outside-air temperatures. The uncoated surface temperatures and outside-air temperatures from April 1997 through August 1997 are slightly higher for the convenience store than for the veterinary clinic and the coated surface temperatures are generally lower, but by less for these months than other months. The shading of the convenience store roof is due to live oak (encina) trees. Differences in shading patterns from year to year are possible.

Table 3 shows monthly average sunlit temperatures on the roof of the fast food restaurant. Its sunlit criterion involves a small difference between the TC2 and RH3 coated surface temperatures because there was no low reflectance surface there. Throughout the project, the air temperatures on the roof of the fast food restaurant are slightly higher than on the veterinary clinic. The fast food restaurant roof was surrounded by a parapet which sheltered its roof somewhat from wind effects. Also, temperatures from a different part of the day were used. The sunlit criterion for the restaurant tended to be satisfied earlier in the morning of sunny days and ceased being satisfied earlier in the evening compared to the veterinary clinic's criterion.

The surface temperatures for the TC2 and RH3 coated surfaces are consistent with the behavior of the solar reflectances. . Figure 2 showed that the solar reflectance of coating TC2 started out slightly lower than the reflectance of coating RH3 and decreased more in the 500 days of the project. Both coatings were brushed on the smooth fast food restaurant roof itself and the smooth EPDM substrate used on this roof for the pieces from which samples were cut off for reflectance measurements. The ceramic-filled TC2 brushed on much thicker and yielded a rougher surface than the acrylic elastomeric RH3. The percent differences between the temperatures of RH3 and TC2 increase in July, August and September 1997 relative to the same months in 1996. The temperatures of both coated surfaces are somewhat lower than those of the coated surfaces on the veterinary clinic in summer 1996. By summer 1997 this is only true for coating 
RH3. The advantage of the smooth-surfaced substrate has disappeared for coating TC2, apparently because it had a rougher surface that encouraged faster weathering than coating RH3. 


\section{HEAT FLUXES THROUGH THE BUILT-UP ROOFS}

The test protocol for this project included measurement of roof heat fluxes. Heat fluxes through the roof deck can be a direct indicator of the effect of a coating on the energy performance of a building because they are the direct effect of the roof on the interior of the building. For the veterinary clinic and three-fourths of the convenience store roofs, however, the heat fluxes through the deck entered an unconditioned plenum space above a drop ceiling. For these areas, the conditioned interior felt the roof heat fluxes more indirectly than for the exposed metal deck of the storeroom in the convenience store. Moreover, roof heat fluxes are also sensitive to the components, especially level of insulation, of the whole roof.

To assure accuracy of measured heat fluxes, the heat flux transducers were calibrated in aged polyisocyanurate insulation and embedded in the middle of the insulation in all three roofs at the federal facility, not on the decks. Deck heat fluxes were predicted as described next. Only results for the built-up roofs are included here. Heat fluxes for coatings RH3 and TC2 on the restaurant roof were smaller than for the built-up roofs due to thicker insulation in the restaurant roof. A sunlit criterion was difficult to implement since there were no large differences between heat fluxes like for the coated and uncoated areas of the built-up roofs.

Despite the careful calibration and installation of the heat flux transducers in all roofs, the one in the uncoated location at the veterinary clinic failed early in the project. Data from the first few weeks of reliable operation were used to verify the accuracy of the one-dimensional transient heat conduction equation programmed into the computer program STAR (Wilkes, 1989) with components and their properties for the roof of the veterinary clinic (see Figure 1) and boundary conditions from inside-surface and outside-surface temperatures measured at the veterinary clinic. See Petrie, et al. (1998) for details. In the thermally massive unshaded roof of the veterinary clinic, STAR was able to follow the diurnal transient behavior very well. The remaining measured heat flux through the coated area was considered sufficient to provide an ongoing measure of STAR's accuracy.

Figure 4 shows typical behavior of measured and predicted heat fluxes in the roof of the convenience store at the uncoated (dashed curves) and coated (solid curves) locations for two sunny days about a year apart. Measured and predicted heat fluxes are shown in the middle of the polyisocyanurate insulation. The predicted heat fluxes for the deck are also shown. The shading of the roof of the convenience store induced irregular transient behavior in the measured heat fluxes. One hour averages captured this behavior as well as the expected diurnal behavior. Figure 3 showed the same irregular behavior imposed on diurnal variations for the outside-surface temperatures just before and after the roof was coated. 
STAR was not able to mirror the measured heat flux behavior given only the hourly surface temperatures as boundary conditions. The solid curves for the coated location show that the predictions for the middle of the insulation compare well, except for a delay, to the measured insulation heat fluxes up to the noon time peak. The predictions do not fall off fast enough to follow the dip at $2 \mathrm{pm}$, overshoot the $4 \mathrm{pm}$ peak, and remain above the measurements the rest of the days. The predictions for the coated heat flux through the metal deck generally follow the predictions for the coated insulation heat flux, wiggling above and below them. This is reasonable for the lightweight roof on the convenience store. Note that the increase in measured heat flux for the coated area after a year of weathering is duplicated by the predictions. The dashed curves for the uncoated heat fluxes show the same inability of the predictions to mirror the measured heat fluxes. The situation is exacerbated by the more severe peaks and valleys of the uncoated heat fluxes. However, there are again small differences between the predicted insulation and deck heat fluxes, much smaller than between the measured and predicted insulation heat fluxes, with the deck fluxes wiggling above and below the predicted insulation fluxes.

Figure 5 shows the same comparisons of heat fluxes for the veterinary clinic as Figure 4 did for the convenience store, except that measured heat fluxes were not available for the uncoated area due to the failure of the heat flux transducer there early in the project. The agreement between the measured and predicted heat fluxes in the middle of the polyisocyanurate insulation under the coated area is excellent on these hot sunny days and both capture the effect of weathering of the coating. Weathering effects do not seem as severe as on the roof of the convenience store, which the measurements of solar reflectance at 500 days for the samples VC and SHP in Figure 2 corroborate. The differences between the predicted coated and uncoated heat fluxes are not as large as on the convenience store either, which is due to the enhanced effect of the shading on the coated area on the convenience store, preferentially shading it near noon when solar irradiation peaks. The predicted heat fluxes through the heavyweight concrete deck of the veterinary clinic are delayed and diminished relative to those through the insulation. The deck heat flux through the uncoated area is positive (into the building) all 24 hours of these sunny hot days. The fresh coating allowed a few hours per day of negative heat fluxes (out of the building) but the weathered coating has lost this advantage or the climatic conditions are slightly more severe.

To generalize the lessons from Figures 3 and 4, Table 4 presents average sunlit roof values for heat fluxes in the same manner as Table 2 did for outside-surface temperatures. Sunlit heat fluxes are included in the monthly averages in Table 4 for times when the coated heat flux was positive and the uncoated heat flux exceeded it by $0.5 \mathrm{Btu} / \mathrm{h} \cdot \mathrm{ft}^{2}\left(1.6 \mathrm{~W} / \mathrm{m}^{2}\right)$. This sunlit criterion is more complicated than for surface 
temperatures but was necessary because heat fluxes routinely became negative at night and still occasionally satisfied the difference. Requiring positive heat fluxes excluded nighttime heat fluxes. The sunlit criteria generally yielded entries for pairs of heat fluxes beginning slightly later in the day than pairs of surface temperatures and continuing later into the early evening.

For the convenience store, the measured heat fluxes and, therefore, their averages, are more accurate. However, the average predicted heat fluxes yield useful information. They show that the percent decreases in heat fluxes predicted through the insulation and the deck due to the coating are the same within 0 to $+2 \%$ for the summer months of June, July, August and September. Hence, for the convenience store on average, the percent decrease in heat fluxes through the deck can be characterized by the behavior of the measured heat fluxes through the insulation. These heat fluxes are proportional to differences between summertime roof temperatures so percentage decreases for them are larger than for the outside-surface temperatures. The fresh coating shows an average heat flux decrease of $54.6 \%$ in heat fluxes in July, August and September 1996 compared to an average 14.0\% outside-surface temperature decrease for the same months in Table 2. The average heat flux decrease falls off to $43.8 \%$ in July, August and September 1997 compared to $11.6 \%$ for outside-surface temperatures.

For the heavyweight concrete-decked roof on the veterinary clinic, the accuracy of the predictions is acceptable for comparisons of the effect of the coating on heat fluxes. This is fortunate because the heat fluxes of direct interest for the effect of the roof on the building interior are those through the deck. They are significantly different from the insulation heat fluxes and yield larger percent decreases for the effect of the coating. For August and September 1996, using the deck predictions, the average percent decrease is $50.9 \%$ compared to an average $12.0 \%$ decrease for outside-surface temperatures in August and September 1996 from Table 2. The average heat flux decrease falls off to $46.9 \%$ in August and September 1997 compared to $10.2 \%$ for outside-surface temperatures.

From the perspective of average heat fluxes through the deck during sunlit times, there is no significant difference in behavior between the lightweight roof on the convenience store, where the effect of the coating is slightly enhanced by the preferential shading, and the heavyweight roof on the veterinary clinic, where deck heat fluxes are delayed by the thermal mass and the coating did not appear to weather as much during the project. However, because the veterinary clinic and three-fourths of the convenience store had an unconditioned plenum shielding the roof from the conditioned interior, the effect of the coating on deck heat fluxes cannot be interpreted as its effect on building heating or cooling loads. 


\section{WHOLE BUILDING MODELING USING DOE2.1E}

Of particular interest in this New Technology Demonstration Program project is the effect of white coatings on the annual cooling energy demand of buildings in the federal sector. Due to the unconditioned plenums under much of the roof of the convenience store and all of the roof of the veterinary clinic, extrapolation to annual energy impact of the trends shown by the heat fluxes through the roofs in Table 4 is very difficult. Even if the effect of the coatings on the annual cooling energy demand of the buildings were obtainable from the heat fluxes in Table 4, the buildings are certainly not typical of all federal buildings and the weather during which the data were obtained is not typical of that for all federal buildings.

At best the buildings can serve as examples of the effect of coatings. In order to maximize their worth as examples, DOE 2.1E modeling of the convenience store and the veterinary clinic was done. This section describes that effort and presents results from the models for the relative effects of the coatings and natural shading on the annual energy demand of these buildings in the climate of the Florida Panhandle.

The test protocol included monitoring of total electricity demand in the all-electric convenience store and veterinary clinic. Pulse-initiating kilowatt-hour meters in each building reported total electricity demand to a pulse counter in the data loggers. Little could be done directly with these data. The high internal electrical loads in the convenience store and the consequent erratic nighttime demand prevented simple correlation of the effect of the coating to total demand (Petrie and Childs, 1997). The essentially zero nighttime and weekend demand in the veterinary clinic did allow generation of monthly average electrical demands during occupied hours. In fact, a comparison between average outside-air temperatures on the roof of the veterinary clinic and average power demand was offered as tentative proof that the coating was saving electricity (Petrie, et al., 1998). The averages before and after the coating was applied were computed when power demand exceeded $1.5 \mathrm{~kW}$. The level of $1.5 \mathrm{~kW}$ was judged to mean that the building was occupied.

Table 5 presents the complete list of monthly average power demand and outside-air temperatures with the criterion that hourly power exceeds $1.5 \mathrm{~kW}$ for the veterinary clinic. Data for May and June 1996 are included to show months before the veterinary clinic roof was coated. The average outside-air temperatures are slightly different for corresponding months in Table 2 and Table 5 because the criteria are different. For example, Table 5 does not include data for any sunny weekend days when the veterinary clinic's HVAC system was not operating.

From Table 5, by comparison of data only for June and August 1996, there is an apparent decrease of $13 \%$ in average power despite a $1.1 \%$ increase in average outside-air temperature. The likely incorrect- 
ness of assigning this as the effect of the coating is brought out by comparing data for May and June 1996 with data for May and June 1997. The opposite conclusion is reached. The same building with a slightly weathered coating on the roof uses $12 \%$ and $14 \%$ more average power for a $2.8 \%$ and $1.6 \%$ decrease in average outside-air temperature in May and June 1997 compared to May and June 1996. Average power does increase for August and September 1997 relative to August and September 1996, consistent with the effect of weathering on white coatings, but the increase averages $14 \%$. This is too much to be due to the slight decrease in the reflectance observed on the veterinary clinic roof. Clearly there are too many uncontrolled variables affecting power demand even for the simple veterinary clinic. A very noticeable effect is that June is the month of highest electricity use in the veterinary clinic despite the milder weather compared to subsequent summer months.

\section{DOE2.1E Modeling}

DOE2.1E models were generated for the veterinary clinic and convenience store and subjected to Typical Meteorological Year climatic data for Apalachicola, Florida, near the federal facility. A successful DOE2 model includes good descriptions of the basic construction features of a building, its heating, ventilating and air conditioning system and schedules for occupancy, lighting, thermostat settings and, especially in the case of the convenience store, internal equipment usage and the shading of the building. Relevant details about the convenience store and the veterinary clinic follow.

The convenience store is a concrete block building with a built-up roof shaded by large live oak trees to the south. A sketch was drawn of the shading pattern in mid-morning of a clear, mid-August day. The shadow cast by the trees covered $27 \frac{1}{2} \%$ of the roof area. A large $50 \%$ transparent rectangle was input as the shading to cast a shadow of equal area at the time of the sketch. So much of the roof is shaded that the instruments were deliberately installed in shaded areas. The original part of the building, about $3060 \mathrm{ft}^{2}$ $\left(284 \mathrm{~m}^{2}\right)$ in floor area, has a wood deck with nominal $2 \times 10$ ceiling joists. This part serves as the store itself and has a suspended ceiling forming an unconditioned plenum with $\mathrm{R}-11 \mathrm{~h} \cdot \mathrm{ft}^{2} \cdot{ }^{\circ} \mathrm{F} / \mathrm{Btu}\left(1.9 \mathrm{~m}^{2} \cdot \mathrm{K} / \mathrm{W}\right) \mathrm{batts}$ laid on the ceiling tiles. Insulated ducts are in the plenum to distribute air heated by electric resistance strip heaters or cooled by a direct expansion evaporator coil. Air temperature is controlled by a thermostat in the store area. Refrigerant lines go to and from a compressor and condenser coil on a concrete pad outside the building. There are also several compressors and condenser coils on other external pads to serve the refrigerators and freezers in the store. No equipment is on the roof. A stockroom, about $950 \mathrm{ft}^{2}\left(88 \mathrm{~m}^{2}\right)$ in area, was built when the building was converted to a convenience store. Its built-up roof is over a metal 
deck and 2 in. $(5.1 \mathrm{~cm})$ of polyisocyanurate insulation and was the site of the instrumented areas. The stockroom is open to the store through a large door-sized archway and is separately heated and cooled by a through-the-wall air-to-air heat pump. Suspended fluorescent fixtures serve the lighting needs of both the store and stockroom. Before the convenience store roof was coated, it was operated 7 days per week from 10 am to $10 \mathrm{pm}$. As of August 1,1996, at the end of the first month after coating, hours were cut back to 9 am to $7 \mathrm{pm}$ weekdays and Saturdays and 11 am to $5 \mathrm{pm}$ on Sundays. The facility's energy management system adjusted the hours of HVAC system operation in response to the new schedule.

The veterinary clinic is a $1500 \mathrm{ft}^{2}\left(140 \mathrm{~m}^{2}\right)$ concrete block building with a built-up roof over $2 \mathrm{in}$. $(5.1 \mathrm{~cm})$ of polyisocyanurate insulation over 2 to 4 in. $(5.1$ to $10.2 \mathrm{~cm})$ of insulating concrete with a 2 to 3 in. $(5.1$ to $7.6 \mathrm{~cm})$ heavyweight concrete deck. It originally housed a radar facility. There are two deciduous trees at the south end of the building that shaded some of the south wall and roof of the building but not the areas that were instrumented. Rectangles, $50 \%$ transparent in summer but $100 \%$ transparent in winter, modeled this shade. A small unconditioned room at a back corner of the building houses the air handler for an air-to-air heat pump which heats and cools the building. The thermostat to control the heating and air-conditioning is in a reception area at the front of the building. Air distribution is in ducts in the plenum above a suspended ceiling. Recessed fluorescent lights are in the ceiling. The building is operated as a small animal clinic from 8 am to 4 pm weekdays, 8 am to 12 noon some Saturdays and is closed most Sundays and holidays. It too is served by the facility's energy management system. There is very little equipment in the building: two refrigerators and miscellaneous office equipment. Regular occupancy is limited to one receptionist and one or two veterinarians and occasional walk-in visitors with pets. The kennels for occasional boarding of pets are outdoors.

To test the accuracy of the DOE2 models of the convenience store and the veterinary clinic, hourly reports were scheduled in DOE2 to print out the roof shading and roof temperatures as well as the total electrical load on the plants specified to separately serve each building. Reports were written hourly for a week in February, June, August and September of 1996 and June, July, August and September of 1997. The months were selected when power measurements were available and to cover the duration of the project. The week in each month was selected so that the measured outdoor-air temperatures, Toa, for each building approximately matched the dry-bulb temperature, Tdb, in the TMY weather file for Apalachicola, Florida.

Figure 6 shows examples of the results after all adjustments in the models. The weeks shown are February 7-13, 1996 and July 19-25, 1997. The TMY Tdb temperatures in general match the measured 
Toa but the measured power in both buildings does not exactly follow the outside-air temperature anyway. Moreover, measured power is more erratic than the predicted power despite considerable effort at scheduling occupancy, lighting and equipment as well as heating and cooling thermostat settings to match the observed power. Note that the DOE2 model successfully followed the change in schedule starting August 1, 1996 in the convenience store. The hours of non-setback power demand in February 1996 are longer than in July 1997. The data loggers were kept on Eastern standard time year round and scheduling was adjusted in the DOE2 models to match.

Daytime peaks were modeled well for the convenience store but the erratic nighttime demand was more difficult to follow. A summer-only equipment schedule was implemented to specify about $5 \mathrm{~kW}$ extra summer demand by the refrigerators and freezers operating in hot weather. The much lower power demand of the veterinary clinic as well as its being closed on weekends shows up clearly in both the measured and predicted power for the veterinary clinic building. The nighttime demand is often nearly zero, which was easier to model than the erratic convenience store situation.

The reflectance of the uncoated roofs on both buildings was assumed to be $10 \%$. The convenience store and veterinary clinic models with coated roofs were run with solar reflectances of $52.5 \%$ and $45 \%$, corresponding to the fresh and weathered values in Figure 2. To the scale of Figure 6, the dashed lines for the weathered value deviate little from the solid curves for the fresh value.

The base cases of a coated and shaded roof on each building with a solar reflectance of $52.5 \%$ were modified to test the effect of shading and no coating as well as the effect of the weathered coating. The results are in Table 6, with total annual energy use and portions for cooling and heating (including supplemental heat for the heat pumps) given in kilowatt-hours for each case. Changes in total energy use do not equal the sum of the changes in cooling and heating energy use because of small changes in other categories of use such as for ventilation fans. Percent changes due to shading, weathering and no coating compared to the base case (shading and fresh coating) are calculated by the formulas in the table above each set.

The annual energy uses for the convenience store are much larger than for the veterinary clinic. The convenience store is larger and has larger internal loads. Hence, the effect of coating the roof and even the small shade trees at the south of the veterinary clinic have a larger percent impact for this building. For both buildings the effect of the changes in Table 6 cause a misleadingly high percent change in the heating energy needs. This is because the annual heating energy itself is small for both buildings.

The decrease of 0.075 in the solar reflectance value for the coating observed over the duration of 
the project has a negligible impact on the cooling energy and total energy for the convenience store. It is not very significant for the veterinary clinic either. The hourly reports showed that peak roof temperatures (at $10 \mathrm{am}$ ) in mid-August were 6 to $7^{\circ} \mathrm{F}\left(3.3\right.$ to $\left.3.9^{\circ} \mathrm{C}\right)$ warmer with the weathered coating on both roofs. The decrease of 0.425 in roof solar reflectance from the fresh coating to no coating caused the roof temperature in the models to increase 31 to $36^{\circ} \mathrm{F}\left(17\right.$ to $\left.20^{\circ} \mathrm{C}\right)$ at peak times without the coating. However, even this change is not very significant for the convenience store and energy savings were likely not noticed in the effects of the change to a shorter schedule just after the convenience store roof was coated. The savings of $7.4 \%$ in cooling energy and $3.2 \%$ in total energy use predicted for the veterinary clinic is encouraging although not as much as the misleading $13 \%$ saving in occupied power obtained by using data in Table 5 for June and August 1996.

The partially transparent rectangles used in the model delivered a peak shading fraction of 0.10 for the convenience store roof and 0.00 for the veterinary clinic roof in mid-August. Relative to the base case, peak roof temperatures without shade were only $1^{\circ} \mathrm{F}\left(0.6^{\circ} \mathrm{C}\right)$ warmer on the convenience store and unchanged for the veterinary clinic. The predictions for the effect of shading are put into perspective by comparing them to the effect of the coating. The $1.8 \%$ effect on cooling of shading the south wall of the veterinary clinic is one-fourth the $7.4 \%$ effect of the coating. Conversely, the $0.9 \%$ effect on cooling of shading for the convenience store is almost twice the $0.5 \%$ effect of the coating. Shading is clearly a more dominant cooling energy saving measure for the convenience store. 


\section{SUMMARY AND CONCLUSIONS}

Support of the federal New Technology Demonstration Program (NTDP) allowed us to learn the effect of radiation control coatings on roofs at a federal facility in the Panhandle of Florida. Two existing rough-surfaced, moderately well-insulated, low solar reflectance built-up roofs (BURs) were spray coated with a white, latex-based product with ceramic beads. Samples of the coated roofs were brought periodically to the laboratory to measure the solar reflectance as the coatings weathered. Relative to the uncoated BUR, the fresh coating increased the solar reflectance from 0.09 to about 0.53 . This freshly coated solar reflectance is at least 0.2 lower than we have observed for similar fresh latex- or acrylic-based coatings on smooth surfaces, including the ceramic coating used on the BURs. In the course of the project, the reflectance for one BUR decreased to 0.42 while the other decreased to 0.50 . In other tests, white coatings on smooth surfaces that have weathered several years show solar reflectances as low as 0.50 to 0.55 .

Beginning several months before the BURs were coated in July 1996 and ending in October 1997, we monitored the power demand of the all-electric buildings that the roofs covered and temperatures and heat fluxes for two instrumented areas on each roof. The data were analyzed for monthly average performance. The BUR whose reflectance decreased to 0.42 was shaded significantly, including the instrumented areas, by trees to the south of its building. We measured about $271 \frac{1}{2} \%$ shading of the roof in mid-August in mid-morning. The other had a heavyweight concrete deck with some shading away from the instruments.

Average decreases in the sunlit temperatures of the coated vs. the uncoated surfaces for August, September and October of 1996 and 1997 show the effects of weathering for assumed comparable climatic conditions. They also show that the shading enhanced the effect of the coating on the significantly shaded roof. The coated instrumented area there was preferentially shaded near noon of sunny days.

\begin{tabular}{l|c|c|c|c|c|c} 
& $8 / 96$ & $9 / 96$ & $10 / 96$ & $8 / 97$ & $9 / 97$ & $10 / 97$ \\
\hline Shaded roof & $14.4 \%$ & $11.7 \%$ & $12.5 \%$ & $13.4 \%$ & $10.1 \%$ & $12.2 \%$ \\
\hline Heavyweight roof & $12.1 \%$ & $12.0 \%$ & $12.9 \%$ & $9.9 \%$ & $10.6 \%$ & $11.6 \%$
\end{tabular}

The data from before the roofs were coated on through two summers with the roofs coated allow models to be calibrated for the roofs and for the whole buildings with and without the coatings. The shading and heavyweight deck presented unique modeling challenges. Calibrated models allow us to generalize the performance of the coatings to address the effect of varying R-value and other roof features, geographic location and solar reflectance, including the effect of weathering. Generalizations are useful to federal building managers seeking to adopt a new technology demonstrated by the NTDP.

Results from a one-dimensional transient heat conduction program, using measured inside-surface 
and outside-surface temperatures as boundary conditions, were compared to heat fluxes measured in the middle of the 2 in.- $(5.1 \mathrm{~cm}-)$ thick polyisocyanurate insulation on each roof. For sunlit times, average heat fluxes through the bottom of each deck for the coated vs. the uncoated surfaces decreased as follows. The percentage decreases are larger than for the surface temperatures at summer conditions because the heat fluxes are the result of temperature differences. Deck heat fluxes are the direct contribution of the roof to the building interior. An unconditioned plenum under the veterinary clinic roof and three-fourths of the convenience store roof prevents us from interpreting deck heat flux decreases as decreases in building cooling load.

\begin{tabular}{l|c|c|c|c|c|c} 
& $8 / 96$ & $9 / 96$ & $10 / 96$ & $8 / 97$ & $9 / 97$ & $10 / 97$ \\
\hline Shaded roof & $55 \%$ & $53 \%$ & $66 \%$ & $43 \%$ & $47 \%$ & $55 \%$ \\
\hline Heavyweight roof & $50 \%$ & $52 \%$ & $63 \%$ & $45 \%$ & $49 \%$ & $51 \%$
\end{tabular}

Whole building models for DOE 2.1E were constructed with the architectural details and operational features of each building. They were subjected to Typical Meterological Year (TMY) climatic data for Apalachicola, Florida, near the federal facility. Verification of model accuracy was achieved by comparing measured and predicted building power for eight weeks throughout the project when air temperatures measured on the roofs approximately matched the TMY dry bulb temperatures.

Large vertical $50 \%$ transparent rectangles south of the building with the shaded roof were used to model the percent shading observed in mid-August. This building had very high internal loads. The effect of shading and the coating on annual energy use showed that the shading was more effective than the coating in decreasing cooling and total load but neither did much. The heating percentage increases are large because of the small amount of heat required by the building in the Florida Panhandle climate.

\begin{tabular}{l|c|c|c} 
Shaded roof & Total & Heating & Cooling \\
\hline$\%$ change (shaded-unshaded)/unshaded for coated roof & $-0.08 \%$ & $+7.5 \%$ & $-0.9 \%$ \\
\hline$\%$ change (coated-uncoated)/uncoated for shaded roof & $-0.05 \%$ & $+4.0 \%$ & $-0.5 \%$
\end{tabular}

The building with the heavyweight concrete-decked roof had small internal loads. For it, the coating noticeably decreased annual and cooling energy use. The small heating load again exaggerated the heating penalty.

\begin{tabular}{l|c|c|c} 
Heavyweight roof & Total & Heating & Cooling \\
\hline$\%$ change (coated-uncoated)/uncoated roof & $-3.2 \%$ & $+6.0 \%$ & $-7.4 \%$
\end{tabular}

Although the white coatings on the rough-surfaced BURs did not increase their solar reflectances as much as white coatings on smooth surfaces, the increase was significant. Temperatures of the roof 
surfaces and heat fluxes through the roof decks were decreased by over $10 \%$ and $45 \%$, respectively, during times the roofs were sunlit. The test buildings had unconditioned plenums under much of their roofs, which is a common feature in commercial buildings. The buildings had other features, such as a heavyweight roof deck and high internal loads, which were more unique. Because of the features of the buildings, effects similar to those seen in the surface temperatures and deck heat fluxes were not seen in the buildings' cooling energy demand. However, no matter if the roof is rough or smooth, this research has shown that white coatings have the potential to save cooling energy if roof heat load is felt directly by the building. 


\section{ACKNOWLEDGMENTS}

The work reported in this paper was done with the support of the U.S. Department of Energy Federal Energy Management Program (FEMP) and carried out under terms of the Stevenson-Wydler Cooperative Research and Development Agreement ORNL 96-0403. The formal agreement is between Lockheed Martin Energy Research Corporation and ThermShield International, Ltd. Lockheed Martin Energy Research Corporation manages Oak Ridge National Laboratory (ORNL) for the U.S. Department of Energy under contract No. DE-AC05-96OR22464. Tyndall AFB and the Burger King Corporation made three buildings available and provided communication lines with which to do remote monitoring. Gulf Power Company, the electric utility serving Tyndall AFB, installed pulse-initiating kilowatt-hour meters for two of the buildings. Other national laboratories are involved in this project. Pacific Northwest National Laboratory did an economic analysis based on information in ThermShield's technology submittal to the New Technology Demonstration Program of FEMP and provided input to an interlaboratory council. The council-which had representation from Lawrence Berkeley National Laboratory, the National Renewable Energy Laboratory, Oak Ridge National Laboratory, and Pacific Northwest National Laboratory-decided to choose the ThermShield coating technology and approved funding of the work plan submitted by the Buildings Technology Center at the Oak Ridge National Laboratory. Lawrence Livermore National Laboratory provided most of the coating applied at Tyndall AFB from a supply purchased from ThermShield for evaluation of its effectiveness in various applications. 


\section{REFERENCES}

Akbari, H., S.J. Konopacki, D.S. Parker, B.A. Wilcox, C.N. Eley, and M.G. VanGeem. 1998. Calculations in support of SSP90.1 for reflective roofs. ASHRAE Transactions, 104 (Part 1).

ASHRAE. 1989. Energy efficient design of new buildings except new low-rise residential buildings. ASHRAE/IES Standard 90.1-1989. Atlanta, GA: Illuminating Engineering Society of North American and American Society of Heating Refrigerating and Air-Conditioning Engineers.

Gartland, L.M., S.J. Konopacki, and H. Akbari. 1996. Modeling the effects of reflective roofing. Proceedings of the 1996 ACEEE Summer Study on Energy Efficiency in Buildings, 4: pp. 4.117-4.124. Washington, DC: American Council for an Energy Efficient Economy.

Konopacki, S.J., H.Akbari, S. Gabersek, M. Pomerantz, and L.M. Gartland. 1997. Cooling energy saving potentials of light-colored roofs for residential and commercial buildings in 11 U.S. metropolitan areas. Report LBL-39433. Berkeley, CA: Lawrence Berkeley National Laboratory.

LBL. 1981. DOE-2 reference manual, version 2.1A. Report LBL-8706, Rev. 2. Berkeley, CA: Lawrence Berkeley National Laboratory.

LBL. 1993. DOE-2 supplement, version 2.1E. Report LBL-34947. Berkeley, CA: Lawrence Berkeley National Laboratory.

Parker, D.S., J.R. Sherwin, and J. Sonne. 1998a. Measured performance of a reflective roofing system in a Florida commercial building. ASHRAE Transactions, 104 (Part 1).

Parker, D.S., Lixing Gu, J.R. Sherwin, Y.J. Huang, L.M. Gartland, and S.J. Konopacki. 1998b. Measured and simulated performance of reflective roofing systems in residential buildings. $A S H R A E$ Transactions, 104 (Part 1).

Petrie, T.W., and PW. Childs. 1997. Radiation control coatings installed on federal buildings at Tyndall Air Force Base. Volume 1: Pre-coating monitoring and fresh coating results. Report ORNL/CON439/V1. Oak Ridge, TN: Oak Ridge National Laboratory.

Petrie, T.W., PW. Childs, and J.E. Christian. 1998. Radiation control coatings installed on roughsurfaced built-up roofs - initial test results. ASHRAE Transactions, 104 (Part 1).

Wilkes, K.E. 1989. Model for roof thermal performance. Report ORNL/CON-244. Oak Ridge, TN: Oak Ridge National Laboratory.

Yarbrough, D:W. 1997 (and earlier). Private communications of measurement results using Devices and Services Company Model SSR-ER Version 5 Solar Spectrum Reflectometer. D.W. Yarbrough, Chairman and Professor, Department of Chemical Engineering, Tennessee Technological University, Cookeville, Tenn. 


\section{TABLES}

Table 1. Solar reflectances of coated and uncoated membranes.

\begin{tabular}{|c|c|c|c|c|c|}
\hline Location $^{a}$ & Sample & $\begin{array}{l}\text { Coated/ } \\
\text { Uncoated }\end{array}$ & Substrate $^{b}$ & Fresh $\rho \pm \sigma^{c}$ & $\begin{array}{l}\text { Weathered } \rho \\
\text { (if available) }\end{array}$ \\
\hline Convenience store & SHP & Coated & Rough surface & $0.543 \pm 0.045$ & $\begin{array}{l}0.472 \text { (after } 118 \text { days) } \\
0.457 \text { (after } 232 \text { days) } \\
0.416 \text { (after } 496 \text { days) }\end{array}$ \\
\hline Veterinary clinic & VC & Coated & Rough surface & $0.530 \pm 0.055$ & $\begin{array}{l}0.488 \text { (after } 118 \text { days) } \\
0.462 \text { (after } 232 \text { days) } \\
0.501 \text { (after } 496 \text { days) }\end{array}$ \\
\hline Store, clinic & UNC3 & Uncoated & Rough BUR surface & & $0.079 \pm 0.017$ (after ??) \\
\hline Restaurant & RH3 & Coated & Smooth EPDM & $0.834 \pm 0.006$ & $\begin{array}{l}0.768 \text { (after } 118 \text { days) } \\
0.723 \text { (after } 232 \text { days) } \\
0.719 \text { (after } 496 \text { days) }\end{array}$ \\
\hline Restaurant & TC2 & Coated & Smooth EPDM & $0.800 \pm 0.011$ & $\begin{array}{l}0.712 \text { (after } 118 \text { days) } \\
0.665 \text { (after } 232 \text { days) } \\
0.632 \text { (after } 496 \text { days) }\end{array}$ \\
\hline BTC & RH2 & Coated & Smooth APP & $0.806 \pm 0.008$ & $\begin{array}{l}0.711 \text { (after } 291 \text { days) } \\
0.696 \text { (after } 496 \text { days) }\end{array}$ \\
\hline BTC & SOL & Coated & Smooth APP & $0.853 \pm 0.005$ & $\begin{array}{l}0.741 \text { (after } 291 \text { days) } \\
0.725 \text { (after } 496 \text { days) }\end{array}$ \\
\hline BTC & TC1 & Coated & Smooth APP & $0.790 \pm 0.005$ & $\begin{array}{l}0.558 \text { (after } 576 \text { days) } \\
0.540 \text { (after } 781 \text { days) }\end{array}$ \\
\hline BTC & UNC2 2 & Uncoated & Smooth APP & $0.074 \pm 0.002$ & 0.057 (after 108 days) \\
\hline BTC & INS & Coated & Smooth EPDM & $0.773 \pm 0.006$ & $\begin{array}{l}0.689 \text { (after } 298 \text { days) } \\
0.539 \text { (after } 664 \text { days) }\end{array}$ \\
\hline BTC & RH1 & Coated & Smooth EPDM & $0.809 \pm 0.002$ & $\begin{array}{l}0.662 \text { (after } 298 \text { days) } \\
0.569 \text { (after } 664 \text { days) }\end{array}$ \\
\hline BTC & UNC1 & Uncoated & Black EPDM & $0.068 \pm 0.001$ & 0.072 (after 496 days) \\
\hline
\end{tabular}

${ }^{a}$ Convenience store, veterinary clinic and restaurant at federal facility in Panhandle of Florida; BTC designates outdoor test facility at U.S. national laboratory in East Tennessee

${ }^{b}$ BUR=built-up roof; EPDM=ethylene propylene diene monomer single ply membrane;

APP=atactic polypropylene polymer single ply membrane

$c_{\rho}=$ solar reflectance; $\sigma=$ standard deviation of measurements 
Table 2. Monthly average sunlit temperatures on the veterinary clinic and the convenience store roofs (Sunlit criterion: Outside uncoated surface temperature, TOSunc Outside coated surface temperature, TOSctd $>7.5^{\circ} \mathrm{F}$ ).

\begin{tabular}{|c|c|c|c|c|c|c|c|c|}
\hline \multirow[b]{2}{*}{ Month } & \multicolumn{4}{|c|}{ Heavyweight Roof on Veterinary Clinic } & \multicolumn{4}{|c|}{ Shaded Roof on Convenience Store } \\
\hline & $\begin{array}{l}\text { Toutside } \\
\text { air }\left({ }^{\circ} \mathbf{F}\right)\end{array}$ & $\begin{array}{c}\text { TOSunc } \\
\left({ }^{\circ} \mathrm{F}\right)\end{array}$ & $\begin{array}{l}\text { TOSctd } \\
\text { ('F) }\end{array}$ & $\begin{array}{c}\text { (unc-ctd)/unc } \\
(\%)\end{array}$ & $\begin{array}{l}\text { Toutside } \\
\left.\text { air ( }{ }^{\circ} \mathbf{F}\right)\end{array}$ & $\begin{array}{c}\text { TOSunc } \\
\left({ }^{\circ} \mathrm{F}\right)\end{array}$ & $\begin{array}{l}\text { TOSctd } \\
\left({ }^{\circ} \text { F }\right)\end{array}$ & $\begin{array}{c}\text { (unc-ctd)/unc } \\
(\%)\end{array}$ \\
\hline JUL 96 & NA & NA & NA & - & 90.8 & 113.0 & 95.1 & 15.8 \\
\hline AUG 96 & 88.0 & 115.7 & 101.7 & 12.1 & 88.2 & 106.9 & 91.5 & 14.4 \\
\hline SEP 96 & 86.5 & 112.4 & 98.9 & 12.0 & 86.4 & 98.4 & 86.9 & 11.7 \\
\hline OCT 96 & 74.2 & 93.2 & 81.2 & 12.9 & 74.8 & 82.5 & 72.2 & 12.5 \\
\hline MAR 97 & 72.2 & 92.9 & 82.2 & $\mathbf{1 1 . 5}$ & 73.2 & 84.8 & 74.9 & 11.7 \\
\hline APR 97 & 72.7 & 97.8 & 85.5 & 12.6 & 74.7 & 99.1 & 83.7 & 15.5 \\
\hline MAY 97 & 79.6 & 109.1 & 96.6 & 11.5 & 82.1 & 109.2 & 93.5 & 14.4 \\
\hline JUN 97 & 86.0 & 117.7 & 105.8 & 10.1 & 87.8 & 121.0 & 104.7 & 13.5 \\
\hline JUL 97 & 90.5 & 121.6 & 109.9 & 9.6 & 93.0 & 124.3 & 110.1 & 11.4 \\
\hline AUG 97 & 89.5 & 118.3 & 106.6 & 9.9 & 93.5 & 120.6 & 104.4 & 13.4 \\
\hline SEP 97 & 87.4 & 112.7 & 100.7 & 10.6 & 87.8 & 98.5 & 88.6 & 10.1 \\
\hline OCT 97 & 74.6 & 91.0 & 80.4 & 11.6 & 75.2 & 85.2 & 74.8 & 12.2 \\
\hline
\end{tabular}

Table 3. Monthly average sunlit temperatures of coatings RH3 and TC2 on the roof of the fast food restaurant (Sunlit criterion: Outside-surface temperature of TC2, Ttc2 Outside-surface temperature of RH3, Trh3 $>2.5^{\circ} \mathrm{F}$ ).

\begin{tabular}{|c|c|c|c|c|}
\hline \multirow[b]{2}{*}{ Month } & \multicolumn{4}{|c|}{ Coated Areas on Roof of Fast Food Restaurant } \\
\hline & $\begin{array}{c}\text { Toutside air } \\
\left({ }^{\circ} \mathbf{F}\right)\end{array}$ & $\begin{array}{l}\text { Ttc2 } \\
\text { ('F) }\end{array}$ & $\begin{array}{l}\text { Trh3 } \\
\text { (०F) }\end{array}$ & $\begin{array}{c}(\text { tc2-rh3)/tc2 } \\
(\%)\end{array}$ \\
\hline JUL 96 & 92.9 & 98.3 & 93.8 & 4.6 \\
\hline AUG 96 & 90.5 & 95.4 & 90.2 & 5.5 \\
\hline SEP 96 & 88.6 & 93.4 & 87.7 & 6.1 \\
\hline OCT 96 & 79.7 & 84.0 & 77.8 & 7.4 \\
\hline MAR 97 & 75.4 & 83.9 & 76.2 & 9.2 \\
\hline APR 97 & 75.5 & 84.7 & 76.6 & 9.6 \\
\hline MAY 97 & 81.6 & 93.2 & 84.2 & 9.7 \\
\hline JUN 97 & 87.1 & 101.1 & 92.3 & 8.7 \\
\hline JUL 97 & 92.1 & 106.8 & 97.9 & 8.3 \\
\hline AUG 97 & 93.5 & 107.8 & 98.9 & 8.3 \\
\hline SEP 97 & 93.2 & 107.9 & 99.1 & 8.2 \\
\hline OCT 97 & 84.2 & 96.3 & 88.6 & 8.0 \\
\hline
\end{tabular}


Table 4. Monthly average sunlit heat fluxes for the veterinary clinic and the convenience store roofs

(Sunlit criterion: Heat flux through coated roof location, HFetd $>0$; Heat flux through uncoated roof location, HFunc -

Heat flux through coated roof location, HFctd $>0.5 \mathrm{Btu} / \mathrm{h} \cdot \mathrm{ft}^{2}$ ).

\begin{tabular}{|c|c|c|c|c|c|c|c|c|c|c|c|c|c|c|c|}
\hline \multirow[b]{2}{*}{ Month } & \multicolumn{6}{|c|}{ Heavyweight Roof on Veterinary Clinic } & \multicolumn{9}{|c|}{ Shaded Roof on Convenience Store } \\
\hline & $\begin{array}{c}\text { Pred. } \\
\text { Insl } \\
\text { HFunc } \\
\left(\mathbf{B} / \mathbf{h} \cdot \mathbf{f t}^{2}\right)\end{array}$ & $\begin{array}{c}\text { Pred. } \\
\text { Insl } \\
\text { HFctd } \\
\left(\mathbf{B} / \mathbf{h} \cdot \mathrm{ft}^{2}\right) \\
\end{array}$ & $\begin{array}{l}\text { (unc- } \\
\text { ctd) ! } \\
\text { unc } \\
(\%) \\
\end{array}$ & $\begin{array}{l}\text { Pred. } \\
\text { Deck } \\
\text { HFunc } \\
\left(\text { B/h.f } \mathbf{f t}^{2}\right)\end{array}$ & $\begin{array}{c}\text { Pred. } \\
\text { Deck } \\
\text { HFctd } \\
\left(\mathbf{B} / \mathbf{h} \cdot \mathbf{f t}^{2}\right)\end{array}$ & $\begin{array}{l}\text { (unc- } \\
\text { ctd) } / \\
\text { unc } \\
(\%) \\
\end{array}$ & $\begin{array}{c}\text { Meas. } \\
\text { Insl } \\
\text { HFunc } \\
\left(\mathbf{B} / \mathbf{h} \cdot \mathbf{f t}^{2}\right) \\
\end{array}$ & 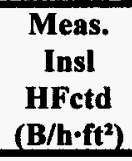 & $\begin{array}{l}\text { (unc- } \\
\text { ctd) / } \\
\text { unc } \\
(\%)\end{array}$ & \begin{tabular}{|c|} 
Pred. \\
Insl \\
HFunc \\
$\left(\mathbf{B} / \mathbf{h}^{\prime} \cdot \mathbf{f}^{2}\right)$ \\
\end{tabular} & $\begin{array}{c}\text { Pred. } \\
\text { Insl } \\
\text { HFetd } \\
\left(\mathbf{B} / \mathbf{h} \cdot \mathrm{ft}^{2}\right) \\
\end{array}$ & $\begin{array}{l}\text { (unc- } \\
\text { ctd)/ } \\
\text { unc } \\
(\%) \\
\end{array}$ & $\begin{array}{c}\text { Pred. } \\
\text { Deck } \\
\text { HFunc } \\
\left(\mathbf{B} / \mathbf{h} \cdot \mathbf{f t}^{2}\right) \\
\end{array}$ & $\begin{array}{c}\text { Pred. } \\
\text { Deck } \\
\text { HFctd } \\
\left(\mathbf{B} / \mathbf{h} \cdot \mathbf{f t}^{2}\right) \\
\end{array}$ & $\begin{array}{l}\text { (unc- } \\
\text { ctd) } / \\
\text { unc } \\
(\%) \\
\end{array}$ \\
\hline JUL 96 & NA & NA & $-\cdots$ & NA & NA & -- & 3.23 & 1.41 & 56.3 & 2.97 & 1.70 & 42.8 & 2.82 & 1.61 & 42.9 \\
\hline AUG 96 & 2.59 & 1.63 & 37.1 & 1.75 & 0.87 & $\mathbf{5 0 . 3}$ & 2.70 & 1.22 & 54.8 & 2.52 & 1.46 & 42.1 & 2.41 & 1.38 & 42.7 \\
\hline SEP 96 & 2.59 & 1.65 & 36.3 & 1.67 & 0.81 & 51.5 & 2.14 & 1.01 & 52.8 & 1.99 & 1.20 & 39.7 & 1.96 & 1.16 & 40.8 \\
\hline OCT 96 & 2.18 & 1.32 & 39.4 & 1.14 & 0.42 & 63.2 & 1.42 & 0.49 & 65.5 & 1.16 & 0.44 & 62.1 & 1.17 & 0.46 & 60.7 \\
\hline MAR 97 & 1.96 & 1.23 & 37.2 & 1.10 & 0.44 & 60.0 & 1.45 & 0.65 & 55.2 & 1.25 & 0.59 & 52.8 & 1.17 & 1.49 & 58.1 \\
\hline APR 97 & 2.40 & 1.55 & 35.4 & 1.49 & 0.71 & 52.3 & 2.25 & 0.94 & 58.2 & 2.01 & 0.95 & 52.7 & 1.91 & 0.83 & 56.5 \\
\hline MAY 97 & 2.66 & 1.80 & 32.3 & 1.66 & 0.84 & 49.4 & 2.64 & 1.30 & 50.8 & 2.60 & 1.49 & 42.7 & 2.41 & 1.31 & 45.6 \\
\hline JUN 97 & 2.72 & 1.92 & 29.4 & 1.73 & 0.98 & 43.4 & 3.29 & 1.87 & 43.2 & 3.29 & 2.18 & 33.7 & 2.93 & 1.92 & 34.5 \\
\hline JUL 97 & 2.76 & 1.98 & 28.3 & 1.71 & 0.99 & 42.1 & 3.57 & 2.10 & 41.2 & 3.69 & 2.66 & 27.9 & 3.27 & 2.28 & 30.3 \\
\hline AUG 97 & 2.68 & 1.90 & 29.1 & 1.64 & 0.90 & 45.1 & 3.51 & 2.00 & 43.0 & 3.41 & 2.30 & 32.6 & 3.01 & 1.97 & 34.6 \\
\hline SEP 97 & 2.44 & 1.62 & 33.6 & 1.52 & 0.78 & 48.7 & 2.14 & 1.13 & 47.2 & 1.87 & 1.18 & 36.9 & 1.86 & 1.17 & 37.1 \\
\hline OCT 97 & 1.74 & 0.97 & 44.3 & 1.34 & 0.66 & 50.7 & 1.75 & 0.78 & 55.4 & 1.40 & 0.68 & 51.4 & 1.49 & 0.77 & 48.3 \\
\hline
\end{tabular}


Table 5. Monthly average occupied power and outsideair temperatures for the veterinary clinic (Occupied criterion: Power $>1.5 \mathrm{~kW}$ ).

\begin{tabular}{l|c|c}
\hline Month & $\begin{array}{c}\text { Power } \\
(\mathbf{k W})\end{array}$ & $\begin{array}{c}\text { Toutside air } \\
\text { ('F) }\end{array}$ \\
\hline MAY 96 & 2.60 & 84.7 \\
JUN 96 & 3.02 & 87.3 \\
JUL 96 & N.A. & N.A. \\
AUG 96 & 2.63 & 88.3 \\
SEP 96 & 2.62 & 87.4 \\
OCT 96 & 2.45 & 73.6 \\
\hline MAR 97 & 2.51 & 75.7 \\
APR 97 & 2.30 & 75.6 \\
MAY 97 & 2.90 & 82.3 \\
JUN 97 & 3.44 & 85.9 \\
JUL 97 & 3.31 & 89.8 \\
AUG 97 & 2.84 & $\mathbf{8 8 . 8}$ \\
SEP 97 & 3.17 & 88.0 \\
OCT 97 & 2.79 & 76.7 \\
\hline
\end{tabular}

Table 6. Comparisons of DOE2 predictions for the effects of fresh and weathered coatings and shading on annual energy use in the veterinary clinic and the convenience store.

\begin{tabular}{l|c|c|c|c}
\hline Category & $\begin{array}{c}\text { Veterinary Clinic } \\
\text { Annual Energy Use } \\
\text { (kWh) }\end{array}$ & $\begin{array}{c}\text { Percent } \\
\text { Change }\end{array}$ & $\begin{array}{c}\text { Convenience Store } \\
\text { Annual Energy Use } \\
(\mathbf{k W h})\end{array}$ & $\begin{array}{c}\text { Percent } \\
\text { Change }\end{array}$ \\
\hline \multicolumn{6}{|c}{ Base Case: Shading and fresh coating (fc: $\rho=0.525)$} \\
\hline Total & $\mathbf{1 0 , 7 3 9}$ & - & $\mathbf{2 1 3 , 7 6 7}$ & - \\
Cooling & 5,037 & - & 27,805 & - \\
Heating & 1,006 & - & 1,150 & - \\
\hline
\end{tabular}

Shading (sh) and weathered coating (wc: $\rho=0.45$ ) vs. base

\begin{tabular}{|c|c|c|c|c|}
\hline & & $(w c-f c) / f c$ & & $(w c-f c) / f c$ \\
\hline Total & 10,806 & $+0.6 \%$ & 213,789 & $+0.01 \%$ \\
\hline Cooling & 5,111 & $+1.5 \%$ & 27,831 & $+0.09 \%$ \\
\hline Heating & 996 & $-1.0 \%$ & 1,145 & $-0.4 \%$ \\
\hline
\end{tabular}

No shade (ns) but fresh coating (fc: $\rho=0.525$ ) vs. base

\begin{tabular}{|c|c|c|c|c|}
\hline & & $($ ns-sh) $/ \mathbf{n s}$ & & $(\mathbf{n S}-\mathbf{s h}) / \mathbf{n s}$ \\
\hline Total & 10,815 & $+0.7 \%$ & 213,943 & $+0.08 \%$ \\
\hline Cooling & 5,130 & $+1.8 \%$ & 28,056 & $+0.9 \%$ \\
\hline Heating & 986 & $-2.0 \%$ & 1,070 & $-7.5 \%$ \\
\hline
\end{tabular}

Shading and no coating (nc: $\rho=0.10$ ) vs. base

\begin{tabular}{|c|c|c|c|c|}
\hline & & nc-fe)/nc & & $(\mathrm{nc}-\mathrm{fc}) / \mathrm{nc}$ \\
\hline Total & 11,095 & $+3.2 \%$ & 213,871 & $+0.05 \%$ \\
\hline Cooling & 5,439 & $+7.4 \%$ & 27,940 & $+0.5 \%$ \\
\hline Heating & 949 & $-6.0 \%$ & 1,106 & $-4.0 \%$ \\
\hline
\end{tabular}




\section{FIGURE CAPTIONS}

Fig. 1. Cross sections of built-up roofs on a convenience store and a veterinary clinic at the federal facility in Florida used for the project.

Fig. 2. History of the solar reflectances of various white coatings on smooth and rough surfaces (see Table 1 for details about coatings).

Fig. 3. Hourly outside-air and outside-surface temperatures for the coated and uncoated locations on the convenience store roof for similar sunny days just before and after the roof was coated.

Fig. 4. Hourly measured and predicted heat fluxes for the coated and uncoated locations on the convenience store roof for similar sunny days one year apart.

Fig. 5. Hourly measured and predicted heat fluxes for the coated and uncoated locations on the veterinary clinic roof for similar sunny days one year apart.

Fig. 6 Comparison between measurements and DOE2 predictions of electrical power for the convenience store and veterinary clinic for a winter and summer week during the project. 
Figure 1

4-Ply Asphalt Built-up Roof

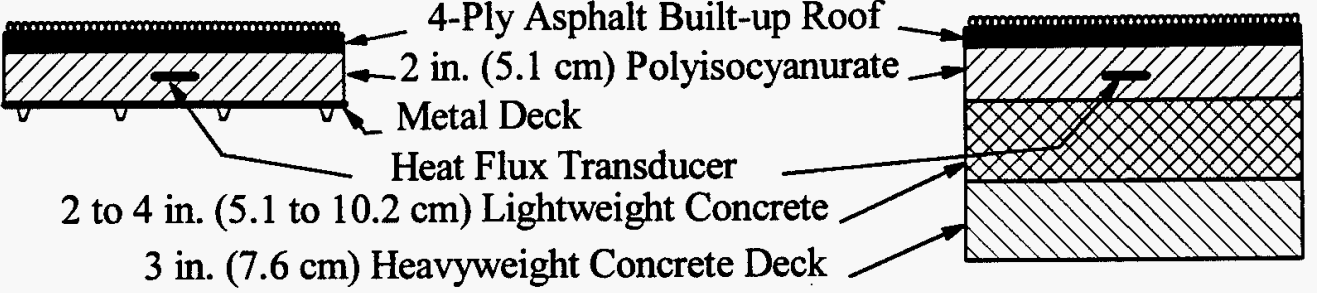

Convenience Store Roof

Veterinary Clinic Roof

Figure 2

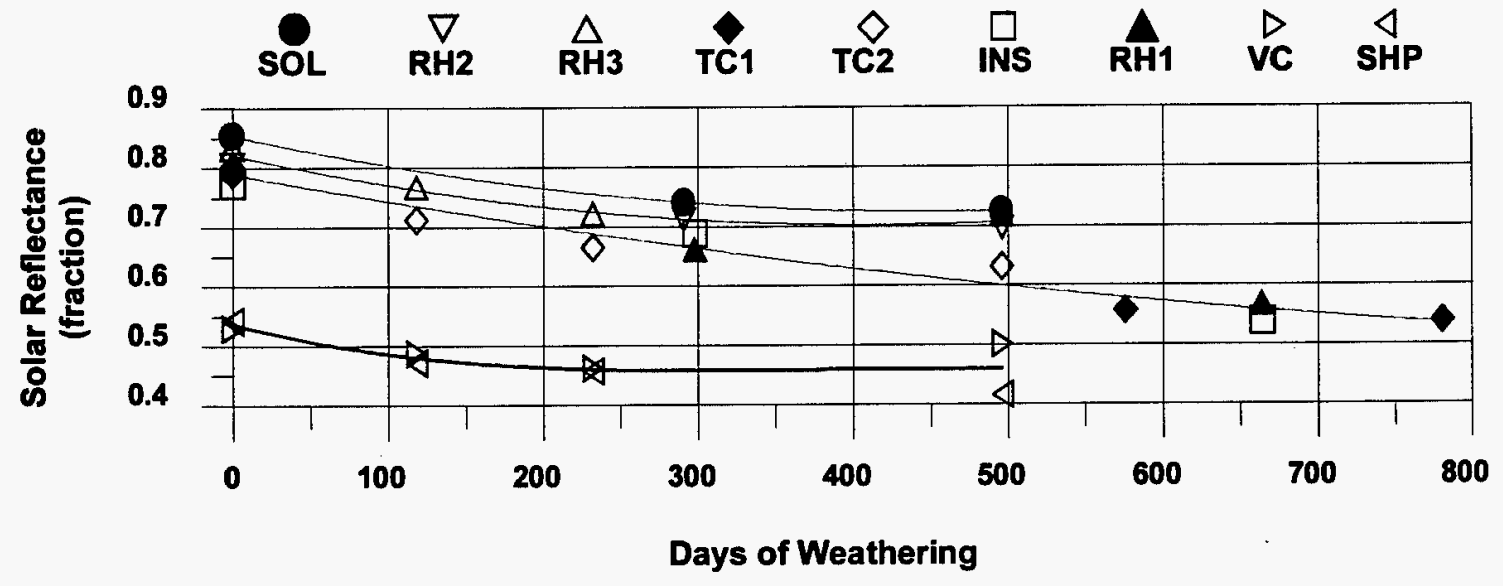

Figure 3

Convenience Store: June 21, 1996 vs. July 30, 1996

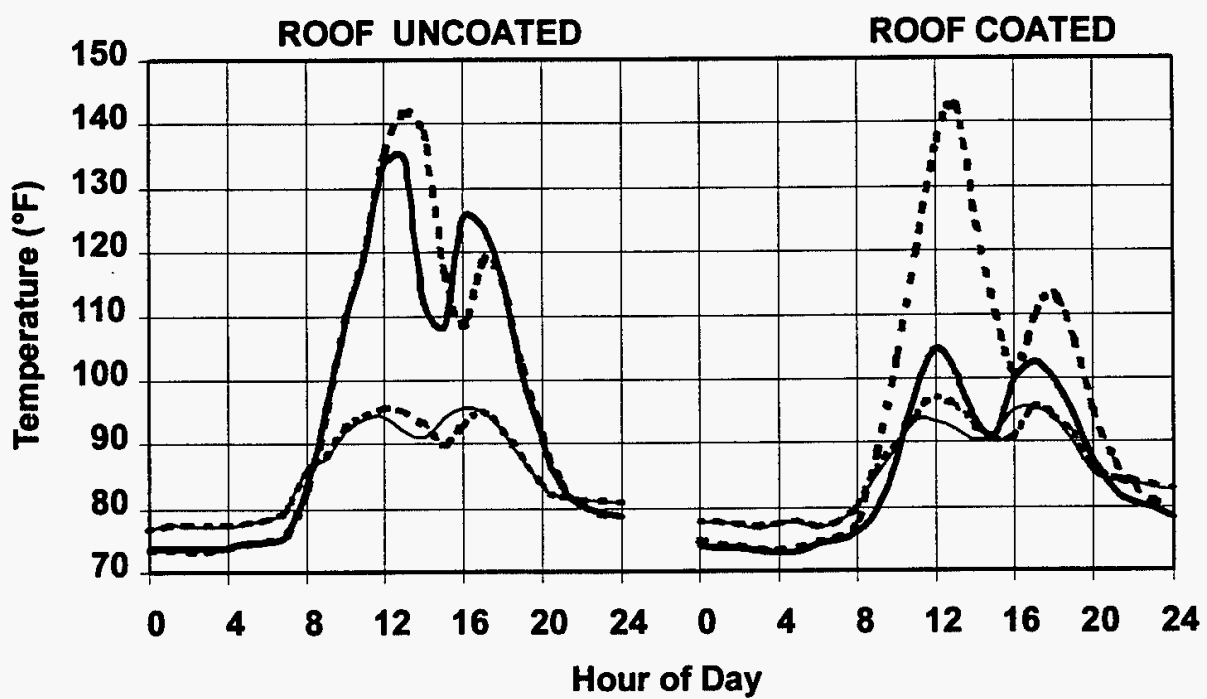

... uncoated Toutside surf

coated Toutside surf

.... uncoated Toutside air coated Toutside air 
Figure 4

Convenience Store: Measured vs. Predicted Heat Fluxes

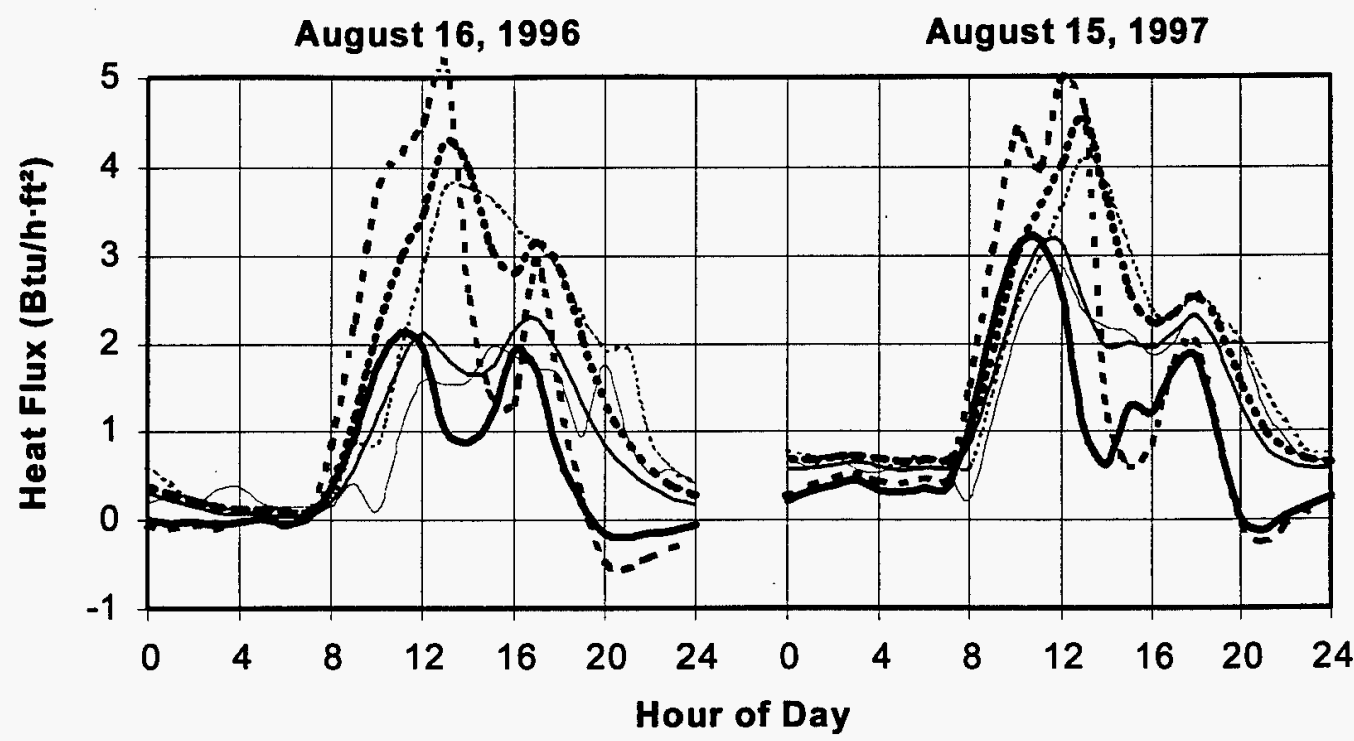

. - . uncoated HF meas. InsI coated HF meas. InsI uncoated HF pred. InsI coated HF pred. InsI uncoated HF pred. Deck coated HF pred. Deck

Figure 5

Veterinary Clinic: Measured vs. Predicted Heat Fluxes

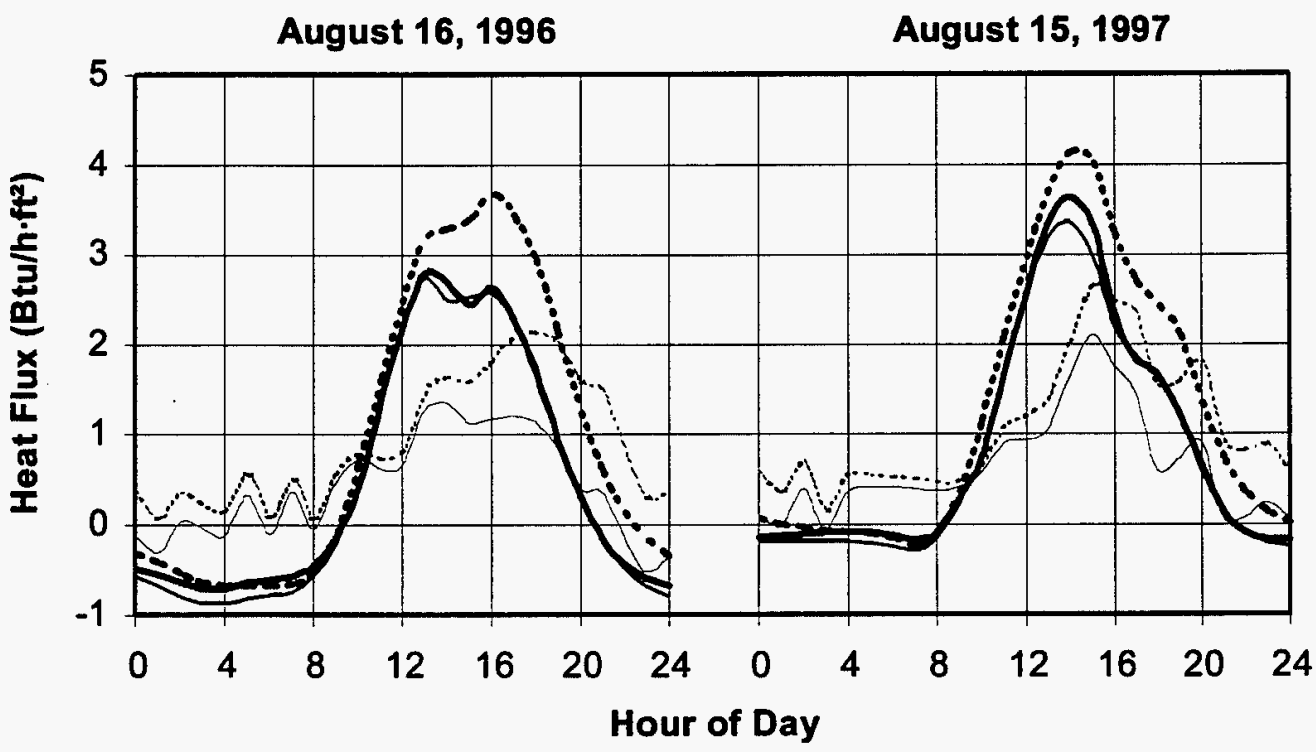

N.A. uncoated HF meas. InsI coated HF meas. InsI uncoated HF pred. InsI coated HF pred. InsI uncoated HF pred. Deck coated HF pred. Deck 
(ঊ.) esnłesed we $\perp$ !! $\forall$ ep!słno

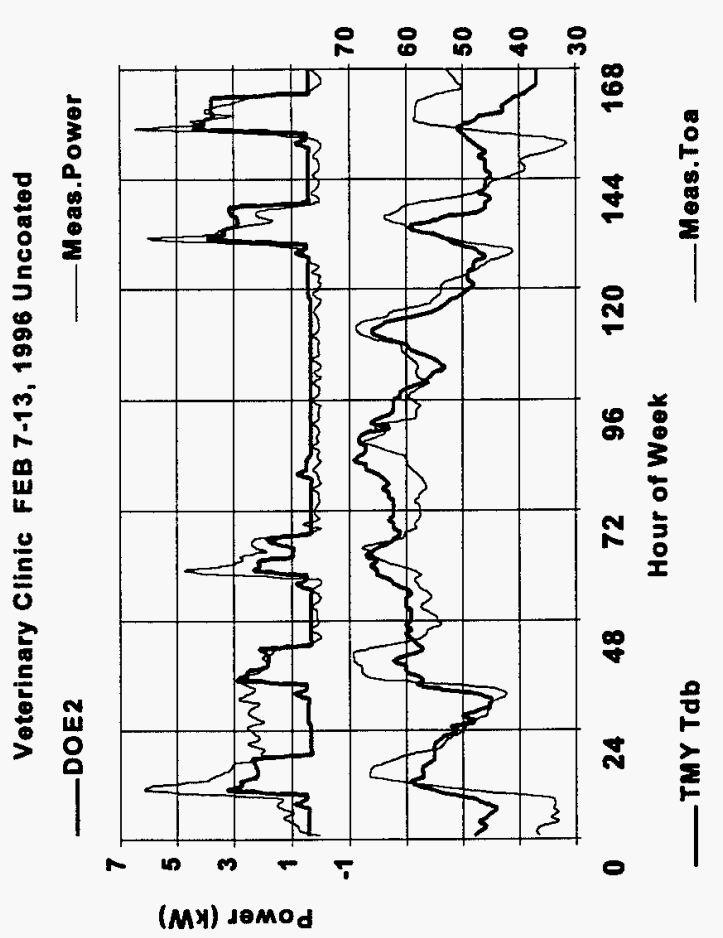

(」.) ednłesed we 1 ג!

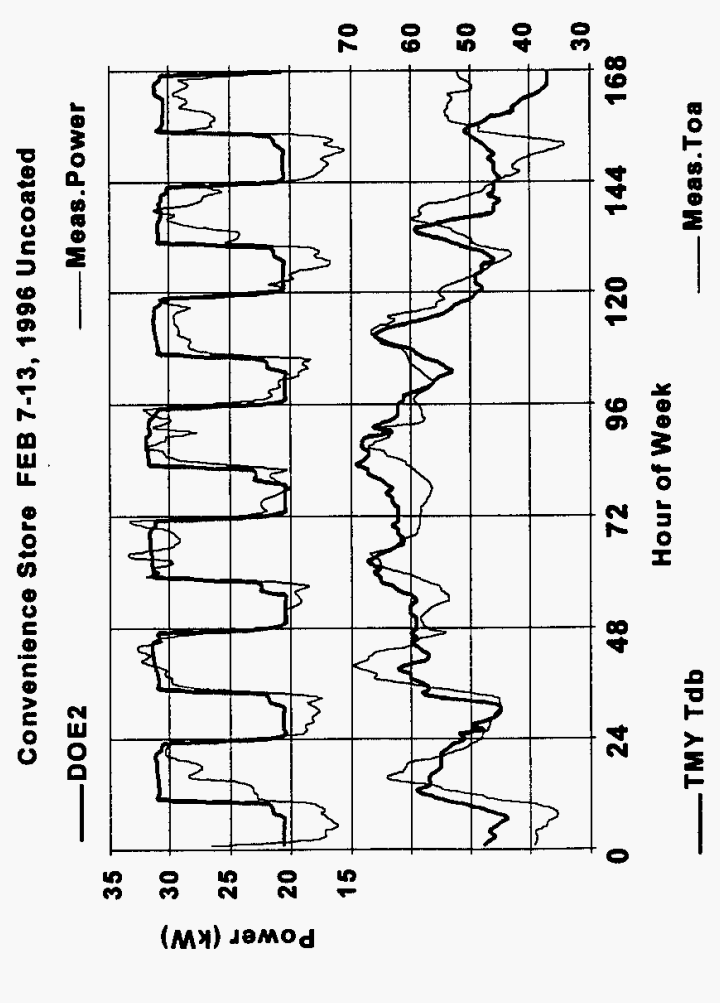

(to) esnłesed we 1 d!

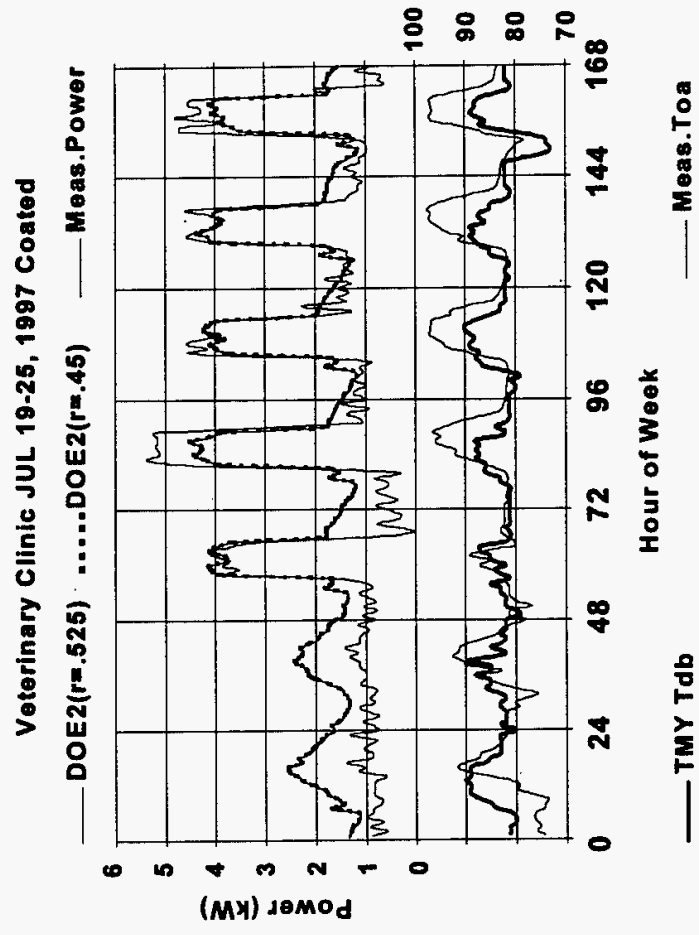

กิ่

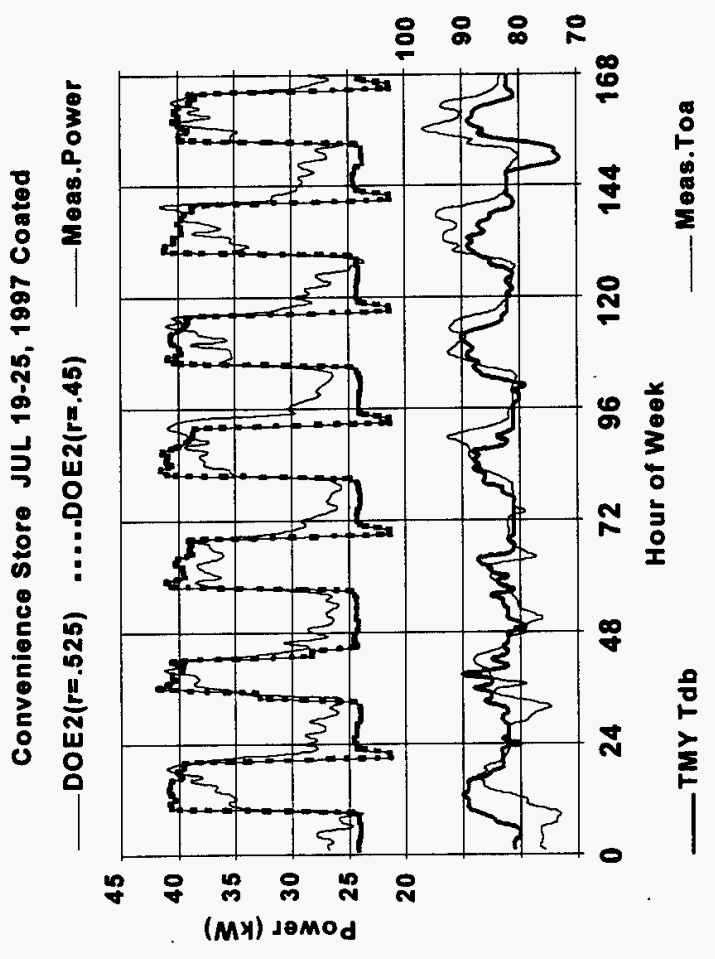




\section{M98004868

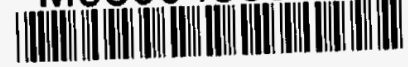

Report Number (14) ORNL/CP- -97535
CONF $-980650-$

Publ. Date (11)

Sponsor Code (18)

199801

UC Category (19)

DOE/EE , XF UC-900, DOE/ER 